American Journal of Pharmaceutical Education 2020; 84 (10) Article 8065.

\title{
COMMENTARY
}

\section{Promoting Creative Problem-Solving in Schools of Pharmacy With the Use of Design Thinking}

\author{
Michael D. Wolcott, PharmD, PhD, a,b Jacqueline E. McLaughlin, PhD, MS \\ ${ }^{a}$ University of North Carolina, Eshelman School of Pharmacy, Chapel Hill, North Carolina \\ ${ }^{\mathrm{b}}$ University of North Carolina, Adams School of Dentistry, Chapel Hill, North Carolina \\ Submitted March 18, 2020; accepted May 20, 2020; published October 2020.
}

\begin{abstract}
Creativity and innovation are commonly discussed topics in the health professions and health professions education. However, initiating creative problem-solving without having a well-defined process in place can be a significant struggle. The design thinking process is gaining popularity in the health professions as a helpful strategy for individuals to address complex problems. In this commentary, we outline the design thinking process and advocate for the use of design thinking by faculty members to promote creative problem-solving in schools and colleges of pharmacy. The design thinking process includes three basic phases (inspiration, ideation, and implementation), each of which is accompanied by various strategies that enable participants to create and organize innovative solutions. Design thinking encourages collaboration, iteration, and optimism using techniques that make addressing ambiguity and failure during the creative process more comfortable. In addition, it pushes participants forward with ideas and can encourage confidence in individual creativity. Engaging faculty members, students, and practitioners in the design thinking process can equip individuals with the techniques and mindset needed to address complex problems in pharmacy education and beyond.
\end{abstract}

Keywords: design thinking, user-centered design, creativity, problem-solving, innovation

Health professions education is riddled with complex problems. These problems are often difficult or impossible to solve as a result of incomplete knowledge, the number of individuals involved, the significant amount of resources needed, and/or the interconnected nature of many problems. ${ }^{1}$ Pharmacy education is no exception to this phenomenon. ${ }^{2}$ Schools and colleges of pharmacy often face complex problems related to managing curricular change, designing quality assessments, supporting students' wellbeing and resiliency, and optimizing the faculty experience, among others. To address these types of challenges, we must adopt useful problem-solving strategies that enable us to develop innovative, creative, and effective solutions. Design thinking is one such problem-solving process, previously applied in architecture, engineering, and computer science, with growing popularity in medical education. ${ }^{3}$ The purpose of this commentary is to outline the design thinking process and describe how it can be used to better understand and address complex problems. This explanation is supplemented

Corresponding Author: Michael D. Wolcott, University of North Carolina at Chapel Hill, Eshelman School of Pharmacy, 321 Beard Hall, Chapel Hill, NC 27599. Tel: 919-537-3854.

Email: wolcottm@email.unc.edu with our experiences with and observations of the application of design thinking in pharmacy education.

\section{The Design Thinking Process}

Imagine being tasked with designing programs to support wellbeing and resiliency at a pharmacy school. The problem is large and significant: it will involve complex constructs (eg, how to define wellbeing and resiliency), it needs to address the concerns of multiple stakeholders (eg, students, faculty members, staff members, preceptors, administrators), and it will likely require substantial resources to establish. We suggest that design thinking can provide a unique approach to address this and similar types of problems in pharmacy education and provide examples from our experience to describe the design thinking process.

The design thinking process provides structure and systematic approaches to creative problem-solving. Design thinking was first described more than 50 years ago ${ }^{4}$ and gained popularity following Tim Brown's description of design thinking in the Harvard Business Review in 2008. ${ }^{5}$ Brown presented the design thinking process as a three-phase cycle: inspiration, ideation, and implementation. ${ }^{6}$ Other disciplines and organizations present design thinking as an expanded five-stage process that 


\section{American Journal of Pharmaceutical Education 2020; 84 (10) Article 8065.}

includes: empathy, define, ideate, prototype, and test. ${ }^{7,8} \mathrm{~A}$ summary of the design thinking process, definitions, and sample strategies are presented in Figure 1. As illustrated by the diagram, design thinking starts with the understanding that it is an iterative process that can occur in cycles.

Inspiration marks the first and most critical phase of design thinking. The goal of this phase is to identify and describe the problem to be addressed. ${ }^{5}$ The inspiration phase has two components: empathize and define. The goal of the empathize step is to connect with the user through observation, interviews, and other strategies to learn about their experience. ${ }^{8,9}$ For example, when designing wellbeing and resiliency programs, this phase could include interviewing students and faculty and staff members. The purpose of this is to describe their current experiences, understand how they perceive wellbeing and resiliency, and identify what they believe contributes to or distracts from wellbeing. At this stage, the perspective of the participants, their challenges, and their needs may differ from what you expected. Information from the empathize step is then used to define the problem, which guides the specific need to be addressed with the solution to be created. ${ }^{6}$ For the wellbeing and resiliency challenge, the problem could be specific to each stakeholder, ie, students may feel that they are overwhelmed by competing priorities, faculty members may feel there is not enough time dedicated to individual work, and staff members may feel that they do not receive sufficient benefits from the institution. Each of these problems serves as a spark for generating ideas in the next phase.
The inspiration phase is critical as it sets the stage for the remainder of the process and has consequences if not properly conducted. For example, if the problem is not clearly defined or targeted in the inspiration phase, resources and time may be wasted later in designing a solution that does not meet the need of users. ${ }^{12}$ Often we tend to skip this step and assume we understand the problem without consulting the appropriate stakeholders or the end user. This can be problematic, especially if we assume that we are similar to the end users. Thus, involving end users and determining their perspectives is critical as they can provide novel insights. Another common error occurs when an existing solution is forced on the perceived problem without fully evaluating the needs of the user. ${ }^{12}$ An example with respect to the wellbeing and resiliency challenge would be if a mobile application were created to deliver tools or resources to the students, faculty, and staff without knowing how they may use or engage with mobile devices. This could be especially problematic if the end users are not comfortable with using technology or resistant to a change in the process.

Ideation is the second phase of the design thinking process. The goal of this phase is to generate as many ideas as possible, ie, brainstorm, with an emphasis on quantity over quality. To optimize the potential for generating creative solutions, design thinking separates divergent and convergent thinking processes. Divergent thinking involves strategies to expand and grow the number of ideas, such as brainstorming, word association, and improvisation games. ${ }^{9-11}$ Convergent thinking aims

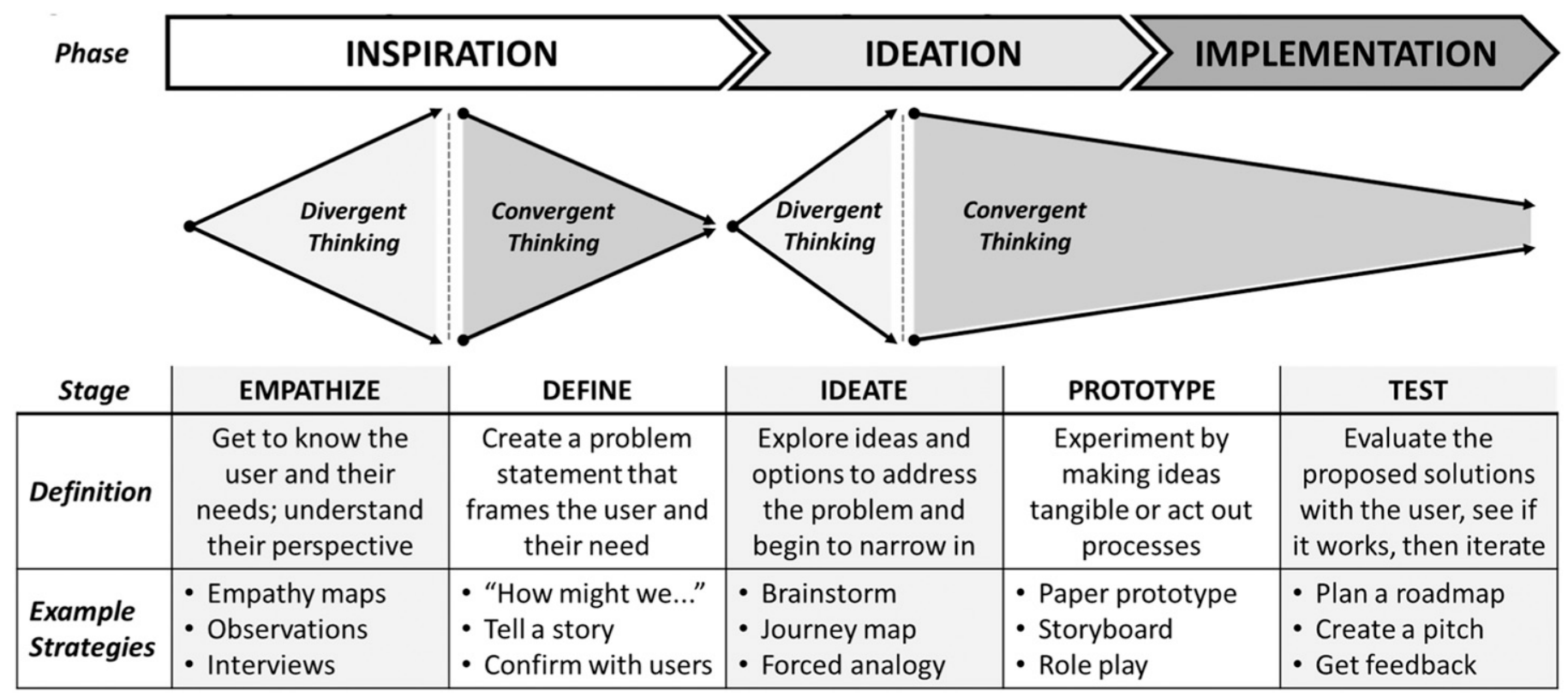

Figure 1. Design Thinking Process, Definitions, and Sample Strategies ${ }^{5-11}$ 


\section{American Journal of Pharmaceutical Education 2020; 84 (10) Article 8065.}

to reduce and distill ideas and involves strategies like evaluating the feasibility or functionality of ideas based on existing constraints, combining ideas to create an alternative solution, and voting on options to gain consensus. $^{9-11}$ This can be a unique opportunity to engage stakeholders in the ideation process; for example, we can facilitate brainstorming with students, faculty members, and staff members to generate ideas on how to improve wellbeing and resiliency programs in the school so that these services better fit their individual needs.

A common challenge during the ideation phase is the tendency to evaluate and critique ideas (ie, converging) as they are created (ie, diverging). This contradictory process can be detrimental because it can stifle the creative process and lead to diminished quality of ideas or create an environment that discourages individuals from sharing. ${ }^{6}$ Design thinking separates these two processes, creating time and space for divergent thinking (eg, brainstorming) prior to any convergent thinking (eg, consensus building). To manage the ideation phase, rules are often added to brainstorming and divergent thinking activities to make them more productive. Example strategies include requesting that individuals defer judgment, using a horn or bell to call out judgmental comments, requiring participants to add on to ideas instead of critiquing them (eg, "yes, and. .."), and asking participants to generate as many ideas as possible (a target of 100 ideas per person is not uncommon). ${ }^{6,7}$ The important message to participants at this stage is that they will later have an opportunity to evaluate and critique the ideas during a convergent process. We continue to see this as one of the most significant barriers in the creative problem-solving process; thus, facilitators are crucial to helping participants separate their thinking so they can be more productive instead of refining their ideas prematurely.

The last phase, implementation, focuses on evaluating the proposed solution and verifying whether it adequately addresses the defined problem. The goal of the implementation phase is to conduct two processes: prototyping and testing. Prototyping includes having end users engage with mock-ups or samples of the proposed solution before a full-scale or finalized version is created. For example, for the wellness and resiliency challenge, the prototype could be in the form of a storyboard that outlines a new process to support students or in the form of a small-scale pilot program to allocate more uninterrupted time for faculty members to work..$^{9-11}$ Early prototyping allows the designer to acquire feedback and gain insights on how to refine the idea to better address the problem. Prototyping leads to a continued convergence of ideas until a proposed final solution is decided on. A more refined product or process is then implemented on a larger scale during the testing phase. Insights from testing often identify whether the problem was adequately addressed in earlier stages and if further refinement is necessary.

A potential pitfall during the implementation phase is becoming too attached to a single solution. During the prototyping process it is encouraged to showcase multiple options and request feedback on how the differing solutions address the problem. Individuals are often more likely to provide constructive feedback when there are several options available. ${ }^{6,7}$ In addition, when prototyping multiple options, specific features that are more desired can be combined into a new solution used in the final testing stage. Prototyping and testing may identify new features about the problem that were not discovered in the earlier phases. In some cases, this may lead to a change in the defined problem itself. Designers should continuously reevaluate whether the defined problem is still applicable or if it must be modified based on new insights about the intended users. It is imperative, however, not to change the defined problem so that the proposed solution fits it better. The problem should only be redefined if there is evidence from the users that indicates they have a different need than initially reported. ${ }^{12}$

\section{Engaging Participants in Design Thinking}

The design thinking process is best implemented in an environment that fosters creativity, which includes having sufficient resources and tools, spaces for creativity, and supportive mindsets. Those interested in using design thinking should first ensure they are appropriately prepared. Materials such as sticky notes, large chart paper, white boards, and markers are staples of design thinking sessions. ${ }^{7}$ In addition, if prototyping is going to be an element of the session, materials such as cardboard, construction paper, tape, and Styrofoam, should be available so that individuals have physical tools that could inspire their creations. Other unique materials include large screen timers so participants can understand how much time there is for a prescribed activity, and an airhorn or bicycle bell that can be used to signal when someone criticizes an idea during a divergent/ brainstorming session (this also helps to maintain a fun and energetic environment). Creating "brainstorming bins" or "creativity kits" (small containers with some of the materials mentioned above) can be helpful as they can be easily transported to the setting for the session.

The physical space chosen for design thinking should also support a productive session. ${ }^{13}$ In general, design thinking requires an environment where individuals can work together; therefore, tables for small groups and mobile furniture is optimal for design thinking sessions. If possible, having a space that is consistently used for design thinking sessions can reinforce a safe environment for creativity. 


\section{American Journal of Pharmaceutical Education 2020; 84 (10) Article 8065.}

Each time an event is located there, participants will be reminded that they have come to engage in exploration and ideation. Ideally, these spaces should be well-lit, offer comfortable seating, and have large tools for writing, such as whiteboards or poster boards. In addition, having beverages and snacks readily available can help sustain productivity. Portable speakers can also be useful when playing music during brainstorming sessions. Design thinking can also be used in virtual environments to foster problem-solving, collect data, and prototype ideas with local, national, or even global stakeholders and collaborators. We have, for example, conducted online focus groups, brainstorming sessions, and prototyping sessions using digital tools and resources. Consideration should be given to holding a session virtually in situations where a face-to-face session is not necessary or possible (eg, because of distance or public health concerns).

The design thinking process requires an openness to creativity and may require a shift in how individuals approach failure or problem-solving. Design thinking is reinforced through seven mindsets (Figure 2), which exemplify the philosophy behind the process. ${ }^{7,14}$ Design thinking centers first on empathy to ensure a continuous focus on the perspective of the user as this is critical to inform the design. In addition, design thinking is inherently optimistic; there is an automatic assumption that a potential solution exists for every problem. The challenge then is for the designer to construct it, using this process and tools, through creativity, iteration, and failure. The

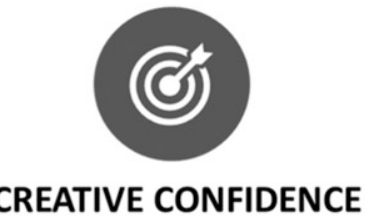

Belief that everyone has creative potential

Goal: Reduces self-doubt and self-imposed limitations

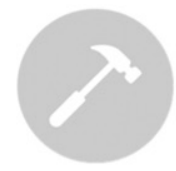

MAKE IT
Convert ideas to tangible or visual products process encourages individuals to move forward quickly without spending excessive time debating issues or ideas. Instead, participants are encouraged to be biased towards action to ensure progress is made. In addition, the design thinking process is highly flexible, which allows it to be applied to multiple contexts. The flexibility requires comfort with ambiguity and a readiness for failure.

Design thinking will take individuals down unknown paths in the pursuit of solving complex problems, and each attempt will provide valuable information. The design thinking process is not linear: each phase informs subsequent iterations but can also be used to refine an earlier phase. The challenge with complex problems is that they can morph based on unpredictable factors. This is why the iterative nature of design thinking is highly emphasized. Finally, design thinking requires creative confidence, ie, the notion that individuals are capable of creating big ideas and acting on them. ${ }^{7}$

\section{Recommendations to Promote Design Thinking}

Design thinking is an effective process for crafting novel solutions within health care and health professions education, which makes it a promising approach to creative problem-solving in pharmacy education., ${ }^{3,5-7}$ Although there is limited research comparing design thinking to other problem-solving strategies, there is a documented impact of using design thinking interventions in various settings. ${ }^{3,15,16}$ Therefore, we offer a series
Goal: Stimulates movement forward and bias to action

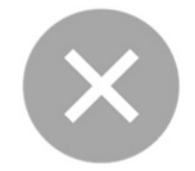

LEARN FROM FAILURE

Each unsuccessful solution provides valuable information

Goal: Promotes risk taking and a focus on learning

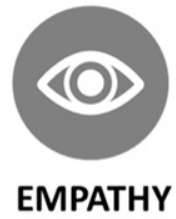

Ability to understand another person's perspective

Goal: Ensures users are at the center of the process

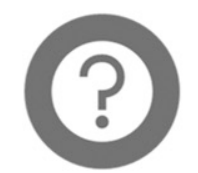

EMBRACE AMBIGUITY

Often start from a place of not knowing or an unclear path

Goal: Encourages trust in the process

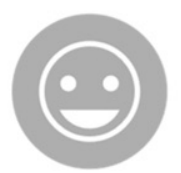

OPTIMISM

Focus on the possibilities and progress that can be made

\section{Goal: Maintains openness and every problem is solvable}

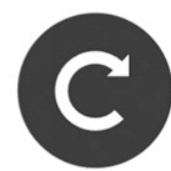

ITERATE, ITERATE, ITERATE

The process is not linear and solutions must be refined

Goal: Allows exploration and to try different approaches

Figure 2. Mindsets That Support Design Thinking ${ }^{7,14}$ 


\section{American Journal of Pharmaceutical Education 2020; 84 (10) Article 8065.}

of recommendations and practical examples to help others integrate design thinking into pharmacy education at the individual, school, and national level.

First, pharmacy educators and administrators should explore design thinking further. While this commentary provides an introduction, there are more print and online resources to discover. For example, individuals can complete certificates or access online resources through design firms such as IDEO (www.ideou.com) or through design schools such as Stanford (dschool.stanford.edu). We encourage others to apply design thinking to their individual challenges: crafting innovative teaching interventions, generating new research ideas, securing grant funding, or piloting new programs. ${ }^{17}$

Second, school leaders should evaluate how design thinking can address organizational problems. Committees and schools can apply design thinking to problems such as revising curricula, crafting innovative practice readiness assessments, and redesigning faculty and staff work experiences. These efforts can also be extended to interprofessional collaborations. One study demonstrated interprofessional leaders could effectively use design thinking to identify educational priorities and develop a strategy to enact them. ${ }^{18}$

Third, national organizations should use design thinking to address complex problems in the profession, such as declining pharmacy school applications, shifts in the job market, accommodating pandemics, or envisioning the future of the profession. National meetings or committees could bring together stakeholders and facilitate hack-a-thons, which are one- to three-day events where all the participants focus on one problem, generate ideas, and pitch their proposals at the conclusion to make progress towards a solution. ${ }^{19}$

Fourth, pharmacy educators should explicitly teach students about design thinking. Accreditation standards stipulate that Doctor of Pharmacy curricula must develop students' abilities to solve problems and apply critical thinking to address health care needs ${ }^{20}$ and design thinking can accomplish this. One study demonstrated that students could be taught design thinking in order to create viable solutions for problems such as how to empower surgical staff in the operating room, redesign more humane psychiatric wards, and decrease attention problems among university students. The researchers found that the experience engaged and positively impacted student learning. ${ }^{21}$ In a Stanford University course, students are taught design thinking to help them plan their careers. The application of this process led to students having improved personal reflection, increased career development self-efficacy, and decreased negative affect towards their careers. ${ }^{22}$
Fifth, schools and organizations should build capacity in design thinking. Design thinking often requires a core group of individuals who engage others in the process (at least two such individuals should suffice). Their role is to engage students, faculty members, staff members, and administrators by providing resources and facilitating design sessions. Specifically, we noted that describing the design thinking process to faculty members and students is necessary but often insufficient to help participants actualize the benefit. We discovered that engaging participants in design thinking without explaining the process in depth is a more effective strategy, especially if it is their first time. We also ensure the design session focuses on a problem that is applicable to them. This initial hands-on exposure helps participants contextualize the process and immediately experience the benefits of design thinking.

Sixth, schools should create organizational cultures that value creativity, exploration, and innovation. We argue the utility of design thinking is maximized when it is reinforced as a problem-solving process across multiple domains at an institution instead of as an isolated tool used periodically with select groups. An organizational shift can result from progressive integration of design thinking strategies to address individual, team, and institutional challenges. It is optimal to demonstrate how design thinking can be applied ubiquitously across the system and to facilitate design sessions that enable faculty members, students, and staff members to express their creativity without fear of judgment.

Overall, there are compelling reasons for pharmacy education to explore design thinking to encourage more creative problem-solving in education and practice. Faculty members, students, and administrators can benefit from learning about the design thinking process and the associated mindsets as it has the potential to alter the culture around creativity and innovation within their institution.

We believe design thinking can support creative problem-solving and equip pharmacy educators to address the complex problems facing the Academy. Design thinking can assist schools, faculty members, students, and administrators as they engage in problemsolving with a new lens. Design thinking supports collaboration, empathy, and optimism, while offering a systematic process for creativity. In addition, design thinking benefits not only those for whom the solution is created, but also those who engage in the process. We strongly encourage individuals with an interest in design thinking to explore the resources and try the strategies provided in this commentary to investigate how it can be applied. 


\section{American Journal of Pharmaceutical Education 2020; 84 (10) Article 8065.}

\section{REFERENCES}

1. Donnelly GF. The transformation of healthcare: A wicked problem. Holist Nurs Pract. 2006 Sep-Oct;20(5):215-216.

2. Irby DM, Cooke M, O'Brien BC. Calls for reform of medical education by the Carnegie Foundation for the Advancement of Teaching: 1910 and 2010. Acad Med. 2010;85:220-227.

3. McLaughlin JE, Wolcott MD, Hubbard D, Umstead K, Rider TR. A qualitative review of the design thinking framework in health professions education. BMC Med Educ. 2019 Apr; 19(1):98.

4. Archer B. Design as a discipline. Design Studies. 1979;1(1): 17-20.

5. Brown T. Design thinking. Harvard Business Rev. 2008;86(6): 84-95.

6. Brown T. Change by Design: How Design Thinking Transforms Organizations and Inspires Innovation. 2nd ed. New York, NY:

Harper Business; 2019.

7. Kelley T. Creative Confidence: Unleashing the Creative Potential Within Us All. New York, NY: Crown Business; 2013.

8. Tools for Taking Action. Stanford school website. https:// dschool.stanford.edu/resources. Accessed January 25, 2020.

9. Design Thinking Methods. IDEO Org Design Kit Web Site. https://www.designkit.org/methods. Accessed January 25, 2020. 10. Curedale R. Design Thinking: Process and Methods. 5th ed. Topanga, CA: Design Community College Inc.; 2019.

11. Kumar V. 101 Design Methods: A Structured Approach to Driving Innovation in your Organization. Hoboken, NJ: Wiley; 2012.

12. Wedell-Wedellsborg T. Are you solving the right problems? Harvard Business Rev. Jan-Feb 2017;76-83.
13. Doorley S, Witthoft S. Make Space: How to Set the Stage for Creative Collaboration. Hoboken, NJ: Wiley; 2012.

14. Mindsets. IDEO Org Design Kit Web Site. https://www. designkit.org/mindsets. Accessed January 25, 2020.

15. Razzouk R, Shute V. What is design thinking and why is it important? Review of Educational Research. 2012;82(3):330-348. 16. Micheli PM, Wilner SJS, Bhatti SH, Mura M, Beverland MB. Doing design thinking: conceptual review, synthesis, and research agenda. J Prod Innov Manag. 2019;36(2):124-148.

17. Kirkland LL, Parham WM, Pastores SM. Approaching hospital administration about adopting cooling technologies. Crit Care Med. 2009;37(7):S290-S294.

18. Cahn P, Bzowyckyi A, Collins L, et al. A design thinking approach to evaluating interprofessional education. J Interprof Care. 2016;30(3):378-380.

19. Silver JK, Binder DS, Zubcevik N, Zafonte RD. Healthcare hackathons provide educational and innovation opportunities: A case study and best practice recommendations. J Med Syst. 2016;40: 177-183.

20. Accreditation Council for Pharmacy Education. 2016. Accreditation standards and key elements for the professional program in pharmacy leading to the doctor of pharmacy degree. https://www.acpeaccredit.org/pdf/Standards2016FINAL.pdf. Accessed January 25, 2020.

21. van de Grift, Tim C, Kroeze R. Design thinking as a tool for interdisciplinary education in health care. Acad Med. 2016;91(9): 1234-1238.

22. Oishi LN. Enhancing Career Development Agency in Emerging Adulthood: An Intervention using Design Thinking [dissertation]. Stanford, CA: Stanford University Press; 2013. 